\title{
Effect of growth arrest on carotene accumulation and photosynthesis in Dunaliella
}

\author{
Pieter Vorst, ${ }^{1}$ Robert L. Baard, ${ }^{2}$ Luuc R. Mur, ${ }^{2}$ Harry J. Korthals ${ }^{3}$ \\ and Herman van den Ende ${ }^{1}$
}

Author for correspondence: Pieter Vorst. Tel: +3120525 7931. Fax: + 31205257934

\footnotetext{
1 Department of Molecular Cell Biology, Section Plant Physiology, University of Amsterdam, Kruislaan 318, 1098 SM Amsterdam, The Netherlands

2 Department of Microbiology, University of Amsterdam, The Netherlands

3 N.I.E. Centre for Limnology, Nieuwersluis, The Netherlands
}

\begin{abstract}
The halotolerant green alga Dunaliella bardawil is known to accumulate $\boldsymbol{\beta}$-carotene in response to stress factors such as high light intensity, high salt concentrations and nutrient limitation. In this report, the accumulation of $\beta$-carotene was studied in cells from nitrate-limited chemostat cultures, in comparison with those of $D$. salina, a strain that does not accumulate $\beta$-carotene under stress conditions. $D$. bardawil responded to growth arrest by accumulating $\boldsymbol{\beta}$-carotene and, to a lesser degree, lutein and zeaxanthin. $A$ substantial fraction of $\beta$-carotene and all the lutein and zeaxanthin was associated with the thylakoid fraction. The accumulation of carotenoids in $D$. bardawil occurred only in the light, but the light intensities were far below those where the photosynthetic rate is maximal. After growth arrest, the amount of chlorophyll (Chl) decreased in both strains. However, in D. bardawil Chl a decreased to a lesser extent in comparison with $\mathrm{Chl} b$, which resulted in an increased $\mathrm{Chl}$ alb ratio. The maximum photosynthetic capacity declined rapidly in both strains after growth arrest. In contrast, the photosynthetic efficiency showed a temporary increase in D. bardawil and a decrease in D. salina. This increase did not occur when carotenogenesis was inhibited by diphenylamine, implying a causal relationship between enhanced carotenogenesis and increase of photosynthetic efficiency. The possible involvement of stress-accumulated carotenoids in photosynthetic activity is discussed.
\end{abstract}

Keywords: Dunaliella, carotenoids, chlorophyll, photosynthesis, growth arrest

\section{INTRODUCTION}

In plants, carotenoids are essential components of the light-harvesting complexes and reaction centres of the photosynthetic apparatus. They are involved in light harvesting, energy transduction and protection against damage by photo-oxidation (Koyama, 1991). Their synthesis is co-ordinatedly regulated with chloroplast development (Kleinig, 1989), but the mechanism of regulation is unknown. It is of interest to study chloroplastassociated carotenogenesis in a system in which the coordination with chloroplast development is released under specific conditions. Such a system is Dunaliella salina Teod., a halotolerant unicellular green alga, containing a single chloroplast. This species synthesizes carotenoids which are typical of green plants, but some isolates, designated as Dunaliella bardawil, have the potential to

Abbreviations: Chl, chlorophyll; DPA, diphenylamine. accumulate carotenoids to as much as $8 \%$ of the dry weight (Ben-Amotz et al., 1989). Carotenoid accumulation is brought about by high light intensities, nutrient stress or high salt conditions. Each of these factors individually has an effect on carotenoid biosynthesis, but when applied together, their effects are additive (Loeblich, 1982).

We show here that growth arrest of nitrate-limited $D$. bardawil cells under moderate light intensities also results in the accumulation of carotenoids, especially $\beta$-carotene. This property was studied in comparison with a carotenoid non-accumulating strain of $D$. salina. Growth arrest also led to changes of photosynthetic characteristics. The interaction between carotenoid accumulation and photosynthesis in these two strains was examined.

\section{METHODS}

Strains and cultivation methods. Dunaliella bardawil (strain 30861 of the American Type Culture Collection) and D. salina 
Table 1. Effect of growth arrest on pigment content of nitrate-limited $D$. bardawil, $D$. salina and $D$. bardawil with DPA

Experimental conditions were as in Fig. 1. The data at day zero are means \pm standard error $(n=4$ for $D$. bardawil and $D$. salina, and $n=3$ for $D$. bardawil + DPA) of the analyses done during steady state growth in the chemostat. The standard error is derived from the data of one experiment.

\begin{tabular}{|c|c|c|c|c|c|c|c|c|c|}
\hline & \multirow{2}{*}{$\begin{array}{l}\text { Time } \\
\text { (d) }\end{array}$} & \multicolumn{8}{|c|}{ Pigment $\left[\mu \mathrm{g}\left(\mathrm{mg}\right.\right.$ protein $\left.\left.{ }^{-1}\right)\right]$} \\
\hline & & $\beta$-Carotene & $\begin{array}{l}\text { Lutein and } \\
\text { zeaxanthin }\end{array}$ & Antheraxanthin & Neoxanthin & Violaxanthin & Chl $a$ & Chl b & Chl $a / b$ \\
\hline \multirow[t]{3}{*}{ D. bardawil } & 0 & $10 \cdot 3 \pm 0 \cdot 4$ & $3 \cdot 1 \pm 0 \cdot 1$ & $0 \cdot 5 \pm 0 \cdot 0$ & $0 \cdot 6 \pm 0 \cdot 0$ & $1 \cdot 2 \pm 0 \cdot 1$ & $34 \cdot 6 \pm 0 \cdot 1$ & $7 \cdot 9 \pm 0 \cdot 1$ & $4 \cdot 4$ \\
\hline & 4 & $116 \cdot 8$ & $8 \cdot 1$ & $0 \cdot 7^{-0}$ & $0.7^{--}$ & 0.5 & $24 \cdot 6$ & $5 \cdot 2^{-}$ & $4 \cdot 7$ \\
\hline & 7 & $190 \cdot 9$ & $12 \cdot 3$ & $0 \cdot 9$ & $0 \cdot 8$ & $0 \cdot 9$ & $29 \cdot 2$ & $5 \cdot 5$ & $5 \cdot 3$ \\
\hline \multirow[t]{3}{*}{ D. salina } & 0 & $4 \cdot 5 \pm 0 \cdot 2$ & $7 \cdot 4 \pm 0 \cdot 3$ & $0 \cdot 7 \pm 0 \cdot 0$ & $1 \cdot 0 \pm 0 \cdot 0$ & $3 \cdot 1 \pm 0 \cdot 1$ & $47 \cdot 7 \pm 2 \cdot 2$ & $12 \cdot 0 \pm 0 \cdot 5$ & $4 \cdot 0$ \\
\hline & 3 & 6.5 & $11 \cdot 0^{-}$ & $1 \cdot 7^{-}$ & 0.9 & $3 \cdot 6^{-}$ & $38 \cdot 2$ & $10 \cdot 4$ & $3 \cdot 7$ \\
\hline & 6 & $6 \cdot 9$ & $10 \cdot 9$ & $1 \cdot 7$ & $0 \cdot 8$ & $4 \cdot 2$ & $21 \cdot 8$ & $7 \cdot 2$ & $3 \cdot 0$ \\
\hline D. bardawil & 0 & $9 \cdot 6 \pm 0 \cdot 5$ & $3 \cdot 0 \pm 0 \cdot 1$ & $0 \cdot 5 \pm 0 \cdot 0$ & $0 \cdot 4 \pm 0 \cdot 0$ & $1 \cdot 1 \pm 0 \cdot 0$ & $29 \cdot 7 \pm 1 \cdot 8$ & $7 \cdot 1 \pm 0 \cdot 4$ & $4 \cdot 2$ \\
\hline \multirow[t]{2}{*}{ + DPA } & 3 & $10 \cdot 3$ & $4 \cdot 1$ & 0.5 & 0.4 & $0 \cdot 2$ & $24 \cdot 7$ & $7 \cdot 7$ & $3 \cdot 2$ \\
\hline & 4 & $14 \cdot 7$ & $4 \cdot 2$ & 0.5 & 0.5 & $0 \cdot 2$ & $24 \cdot 7$ & $7 \cdot 5$ & $3 \cdot 3$ \\
\hline
\end{tabular}

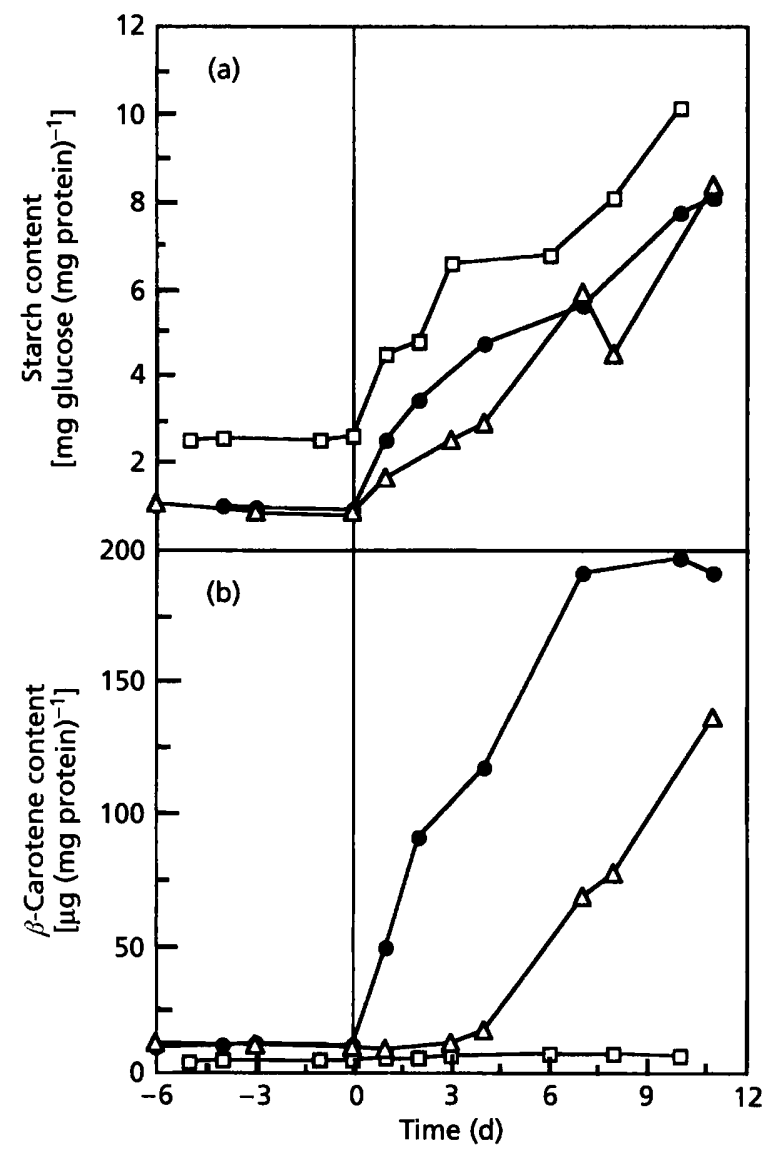

Fig. 1. Effect of growth arrest on (a) starch and (b) carotenoid accumulation in nitrate-limited cells of $D$. bardawil $(O)$ and $D$. salina ( $\square$ ). At time zero the nutrient supply to the chemostat was terminated. At the indicated times the content of $\beta$ carotene was analysed, using HPLC (system I). The data are single determinations. The data of $D$. bardawil with DPA $(\triangle)$ were normalized to the data of $D$. bardawil without DPA by multiplying by a factor of 1.14, based on the slight difference in protein content per cell during the steady state before growth arrest. (strain 9 of the Institute of Plant Physiology of the Russian Academy of Sciences, Moscow) were used.

The algae were cultivated in modified Bold's Basal Medium (Harris, 1989) which consisted of $\mathrm{NaNO}_{3}(2.94 \mathrm{mM}), \mathrm{MgSO}_{4}$ $(0.3 \mathrm{mM}), \mathrm{CaCl}_{2}(0.17 \mathrm{mM}), \mathrm{K}_{2} \mathrm{HPO}_{4}(0.42 \mathrm{mM}), \mathrm{KH}_{2} \mathrm{PO}_{4}$ $(1.29 \mathrm{mM})$, FeNaEDTA $(0.068 \mathrm{mM}), \mathrm{NaHCO}_{3}(5 \mathrm{mM})$ and $\mathrm{NaCl}(1 \mathrm{M})$, and micronutrients according to Wiese (1965): $\mathrm{H}_{3} \mathrm{BO}_{3}(9 \cdot 7 \mu \mathrm{M}), \mathrm{MnSO}_{4}(1.79 \mu \mathrm{M}), \mathrm{NaVO}_{3}(0.52 \mu \mathrm{M}), \mathrm{ZnSO}_{4}$ $(0.15 \mu \mathrm{M}), \quad \mathrm{CuSO}_{4} \quad(0.06 \mu \mathrm{M}), \mathrm{CoSO}_{4} \quad(0.02 \mu \mathrm{M})$ and $\left(\mathrm{NH}_{4}\right)_{6} \mathrm{Mo}_{7} \mathrm{O}_{24}(0.003 \mu \mathrm{M})$. The medium was sterilized by autoclaving at $120^{\circ} \mathrm{C}$. The phosphate components were autoclaved separately and the $\mathrm{NaHCO}_{3}$ solution was filter-sterilized before being added to the sterilized medium.

Stock cultures were routinely maintained on $1.5 \%(\mathrm{w} / \mathrm{v})$ agar slants of the same medium, except that the phosphate components and $\mathrm{NaHCO}_{3}$ were autoclaved together with the medium. The cultures were kept at $19^{\circ} \mathrm{C}$ and illuminated with two TL $58 \mathrm{~W} / 33$ white fluorescent tubes together with a HPI/T $400 \mathrm{~W}$ daylight lamp (Philips) at an average light intensity of $150 \mu \mathrm{mol} \mathrm{m} \mathrm{m}^{-2} \mathrm{~s}^{-1}$. A $12 \mathrm{~h}$ light $/ 12 \mathrm{~h}$ dark regime was applied. Stock cultures were transferred to fresh agar slants every 6 to 8 weeks.

Chemostat cultures were carried out at $28^{\circ} \mathrm{C}$ in 11 culture vessels, containing $565 \mathrm{ml}$ of medium. Continuous one-sided illumination was provided by a HPI/T $400 \mathrm{~W}$ daylight lamp at an average light intensity of $100 \mu \mathrm{mol} \mathrm{m}^{-2} \mathrm{~s}^{-1}$ in the centre of the culture, as measured with a Li-cor model LI-185B photometer equipped with a LI-190SB quantum sensor. Batch cultures $(50 \mathrm{ml})$ at the beginning of the stationary phase, were used as inoculum. The cultures were aerated with $2 \%(\mathrm{v} / \mathrm{v})$ $\mathrm{CO}_{2}$ and stirred every $6 \mathrm{~h}$ for $1 \mathrm{~min}$, and also prior to sampling with a magnetic Teflon-coated rod. Cells that adhered to the glass wall were regularly scraped off, using the magnetic Tefloncoated rod. Nitrate limitation was imposed by reducing the nitrate content of the medium to $10 \%$ of the original amount. The specific growth rate was maintained at $0 \cdot 8 \mathrm{~d}^{-1}$. This resulted in a cell density of $2 \times 10^{5}$ cells ml $\mathrm{m}^{-1}$ for $D$. bardawil and $10^{6}$ cells $\mathrm{ml}^{-1}$ for $D$. salina. Interrupting the medium supply to the culture resulted in immediate growth arrest. 
Table 2. Distribution of carotenoids in whole cells and isolated thylakoids in nitrate-limited $D$. bardawil after growth arrest

Data for the 'cells' fraction represent total pigments; 'thyl' is the thylakoid fraction from the cells, isolated as described in Methods. Pigments were extracted from cells and freeze-dried thylakoids with acetone and hexane and analysed by HPLC (system II). ND, Not detected.

\begin{tabular}{|cccccc|}
\hline \multirow{2}{*}{$\begin{array}{c}\text { Time Fraction } \\
\text { (d) }\end{array}$} & \multicolumn{4}{c|}{ Pigments/Chl $\boldsymbol{a}$ (molar ratio) } \\
\cline { 3 - 6 } & & $\boldsymbol{\beta}$-Carotene & Lutein & Zeaxanthin & Chl $\boldsymbol{a}$ \\
\hline \multirow{2}{*}{0} & Cells & 1.14 & 0.18 & ND & 0.39 \\
& Thyl & 0.39 & 0.20 & ND & 0.45 \\
\multirow{2}{*}{3} & Cells & 12.06 & 0.91 & 0.32 & 0.40 \\
& Thyl & 3.13 & 1.06 & 0.36 & 0.44 \\
4 & Cells & 8.69 & 0.61 & 0.21 & 0.32 \\
& Thyl & 2.75 & 0.59 & 0.20 & 0.41 \\
10 & Cells & 22.24 & 0.60 & 0.19 & 0.26 \\
& Thyl & 2.55 & 0.47 & 0.23 & 0.32 \\
\hline
\end{tabular}

Thylakoid isolation. Thylakoids were isolated according to Ben-Amotz et al. (1982), with slight modifications. Cells were harvested at $1600 \mathrm{~g}$ for $5 \mathrm{~min}$. The algal pellet was resuspended in $25 \mathrm{ml} 30 \mathrm{mM} \mathrm{NaCl}$ and centrifuged at $1600 \mathrm{~g}$ for $5 \mathrm{~min}$. The pellet was resuspended in $10 \mathrm{ml}$ water and after mixing thoroughly for $1 \mathrm{~min}$, centrifuged at $44 \mathrm{~g}$ for $5 \mathrm{~min}$. The supernatant was centrifuged at $12000 \mathrm{~g}$ for $10 \mathrm{~min}$. The pellet fraction was washed once in water and contained the thylakoids while the supernatant fraction contained carotene globules.
Pigment analysis. Pigments were analysed by HPLC (system I) as described by Van der Staay $e t$ al. (1992). Lutein and zeaxanthin were separated by HPLC (system II) as described by Korthals \& Steenbergen (1985), with some modifications. A linear gradient was used. Phase A (hexane with $0.02 \%$ water) and phase $B$ (acetone with $0.5 \%$ methanol) were mixed from an initial value of $20 \% \mathrm{~B}$ to $30 \% \mathrm{~B}$ in $12 \mathrm{~min}$. The flow rate was $1.5 \mathrm{ml} \mathrm{min}-1$ Pigments were detected with a HP 1040 diode array detector.

Photosynthesis. Photosynthesis versus illumination (P-I) curves were made by measuring oxygen production in whole cells using a Clark-type electrode as described by Dubinsky et al. (1987) at $28^{\circ} \mathrm{C}$. From these curves maximal photosynthetic rates $\left(P_{\text {MAX }}\right)$ and light utilization efficiencies $(\alpha)$ were derived (Falkowski, 1984). During the transfer from the culture vessel to the reaction vessel the cell samples were kept in the dark. The rate of oxygen production by isolated thylakoids was measured using a Clark-type electrode at $20^{\circ} \mathrm{C}$ with red light illumination $(\lambda>600 \mathrm{~nm})$ at saturated light intensity and $\mathrm{K}_{3} \mathrm{Fe}(\mathrm{CN})_{6}$ or benzyl viologen as electron acceptor.

Excitation fluorescence of isolated thylakoids. Fluorescence of Chl a was measured on a SLM-aminco spf-500 spectrofluorometer at room temperature. The thylakoid suspension was diluted to an $\mathrm{OD}_{663}$ of 0.2 and placed in a $1 \mathrm{~cm}$ path-length four-sided quartz cuvette. Excitation ranged from 350 to $680 \mathrm{~nm}$ with a step size of $1 \mathrm{~nm}$; emission of Chl $a$ was measured at $690 \mathrm{~nm}$.

Chemical analyses. Cellular starch content was determined as described by Herbert $e t$ al. (1971), using a solution of $2 \mathrm{mg}$ anthrone $\mathrm{ml}^{-1}$ in $98 \%$ sulphuric acid, with D-glucose as standard. Cells were freeze-dried before analysis. Protein content was estimated according to Herbert $e$ t al. (1971), with bovine serum albumin as a standard. Cells were freeze-dried and boiled for $5 \mathrm{~min}$ in $1 \mathrm{M} \mathrm{NaOH}$ before analysis. Nitrate levels in culture liquids were measured according to Kempers \& Luft (1988).

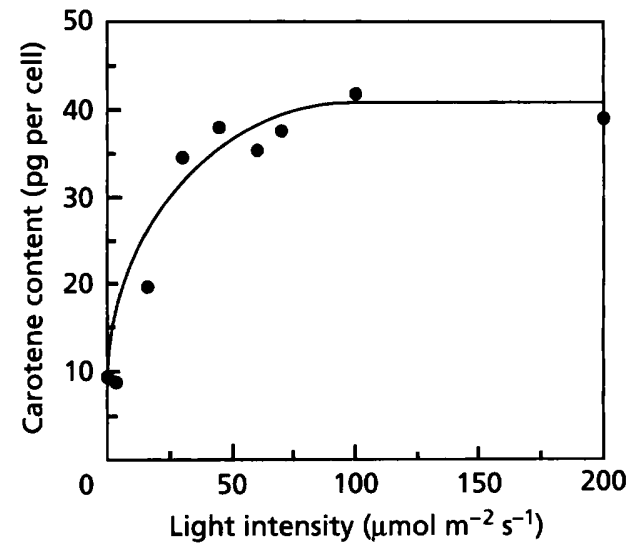

Fig. 2

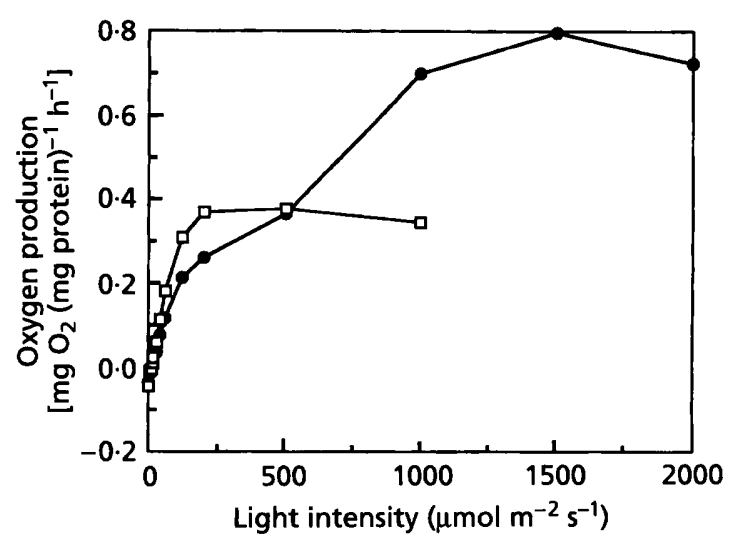

Fig. 3

Fig. 2. Light dependency of carotenogenesis in D. bardawil after $5 \mathrm{~d}$ of growth arrest. Cells were taken from the $24 \mathrm{~h}$ effluent of the chemostat at day 0 and incubated at room temperature. Carotene content was estimated by extracting $10 \mathrm{ml}$ of cell culture with $80 \%$ acetone and the absorption was measured at $450 \mathrm{~nm}$ in a Perkin-Elmer Hitachi 200 spectrophotometer. Carotene content was calculated using the equations of Lichtenthaler (1987). The data are combined from two independent experiments with a different range of light intensity. The average carotene concentration at $t=0$ was $8 \mathrm{pg}$ per cell.

Fig. 3. Photosynthesis versus illumination curves of $D$. bardawil $(O)$ and $D$. salina $(\square)$ during steady state growth in the chemostat. 
Nitrate was reduced to nitrite, which was assayed using $1 \%$ sulphanilamide in $35 \% \mathrm{HCl}$ and $0.3 \% \mathrm{~N}$-(1-naphthyl)ethylenediamine dihydrochloride in $1 \% \mathrm{HCl}$ as reagents. Diphenylamine (DPA) (Merck) was used as an inhibitor of carotene biosynthesis. It was added to the culture as a solution in ethanol $(0 \cdot 12 \%)$, at a final concentration of $40 \cdot 6 \mu \mathrm{M}$.

\section{RESULTS}

Two species of Dunaliella, D. bardawil and D. salina, were cultivated under identical conditions. $D$. bardawil is capable of accumulating large amounts of carotene (BenAmotz et al., 1982), in contrast to D. salina. The two species differ in size, $D$. bardawil being approximately four times larger than $D$. salina. This resulted in a difference in cell-based protein and $\mathrm{Chl}$ content. Comparisons were therefore made on a protein basis. The genetic relationship between $D$. bardawil and $D$. salina was not investigated.

The two species were cultivated in chemostat cultures with nitrate limitation. The nitrate level of the culture liquid inside the culture vessel was below the detection limit $(0 \cdot 2 \mu \mathrm{M})$. A steady state situation, in which the rate of growth can be regulated by manipulating the rate of

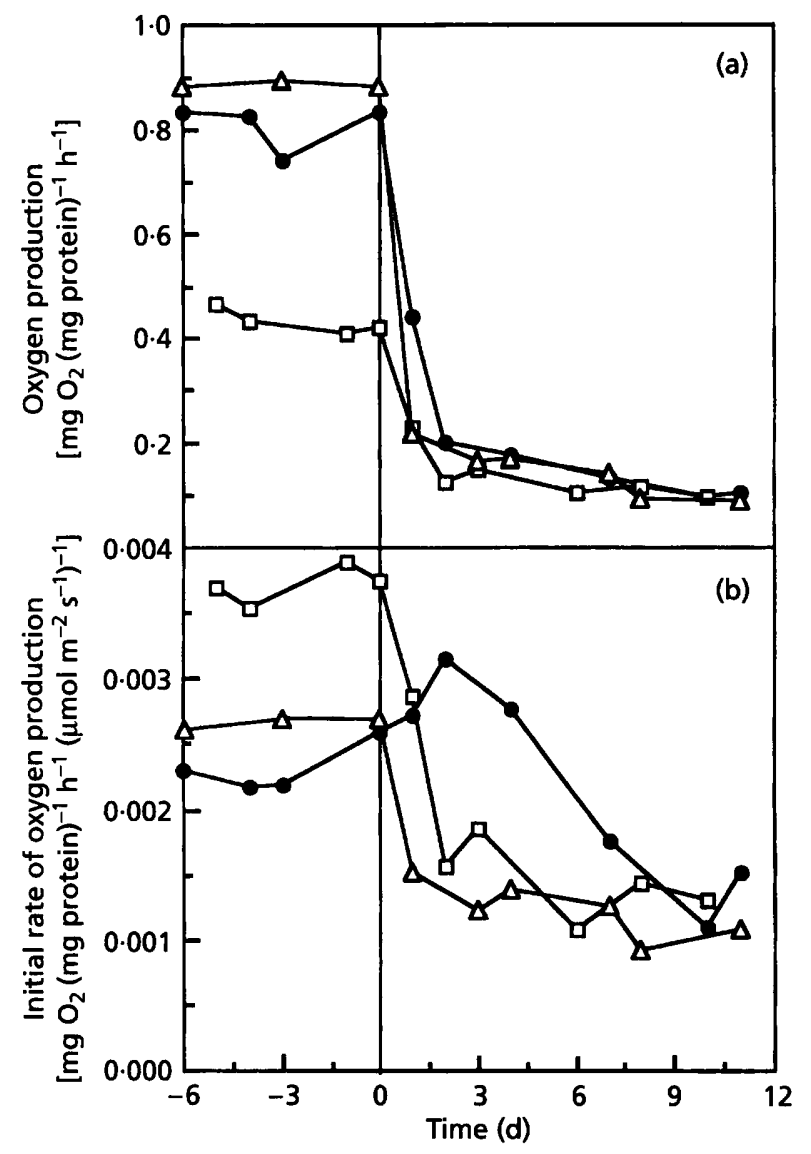

Fig. 4. Effect of growth arrest in nitrate-limited cells of $D$. bardawil (O) and $D$. salina $(\square)$ on photosynthetic parameters. (a) Photosynthetic capacity $\left(P_{\text {MAX }}\right)$; (b) photosynthetic efficiency $(\alpha) . \triangle$, D. bardawil+DPA. Experimental conditions were as in Fig. 1. medium supply to the chemostat vessel, was easily achieved. Although nitrate limitation was used, the carotenoid content of $D$. bardawil was comparable to that of exponential phase cells, grown on complete medium in batch cultures (data not shown). When the medium supply was arrested, cell proliferation stopped immediately, which was accompanied by an increase of starch content in both species (Fig. 1a). Only D. bardawil exhibited in addition a considerable increase in $\beta$-carotene content (Fig. 1b). This could be inhibited by DPA, which was added at the time that growth arrest was imposed. After $4 \mathrm{~d}$, this treatment was no longer effective, indicating a possible inactivation of DPA. The inhibitor had no significant effect on the accumulation of starch.

$\beta$-Carotene was the major carotenoid that accumulated in $D$. bardawil after growth arrest (Table 1). There was also a marked increase in the content of lutein and zeaxanthin (Table 1). This is in agreement with previous studies of stress-induced carotenogenesis in this organism (Borowitzka et al., 1990). In comparison to lutein and zeaxanthin, the other xanthophylls are less abundant in both species of Dunaliella (Table 1). The content of neoxanthin and violaxanthin in both strains hardly changed after growth arrest while antheraxanthin increased more in $D$. salina than in $D$. bardawil. In DPA-treated cells of $D$. bardawil the content of violaxanthin decreased considerably.

Ben-Amotz et al. (1987) showed that the accumulated $\beta$ carotene was, to a large extent, deposited in oily globules in the stroma fraction of the chloroplasts. Table 2 shows, nevertheless, that a substantial fraction of the accumulated $\beta$-carotene was associated with the thylakoid fraction. The ratio of $\beta$-carotene/Chl $a$ in the thylakoids increased by a factor of eight during growth arrest and lutein and zeaxanthin were quantitatively recovered in the thylakoid fraction.

The accumulation of carotenoids in $D$. bardawil was enhanced in the light, as shown in Fig. 2. The light stimulation was saturated at approximately $100 \mu \mathrm{mol} \mathrm{m} \mathrm{m}^{-2} \mathrm{~s}^{-1}$, and was far below the light intensity where the photosynthetic rate is maximal ( $P_{\text {MAX }}$ ) which was about $1500 \mu \mathrm{mol} \mathrm{m} \mathrm{m}^{-2} \mathrm{~s}^{-1}$ for $D$. bardawil and $250 \mu \mathrm{mol} \mathrm{m}^{-2} \mathrm{~s}^{-1}$ for D. salina (Fig. 3). Thus, this system was considered suitable to study the interference of carotenogenesis with photosynthesis that occurs at low light intensity.

After growth arrest, the amount of $\mathrm{Chl}$ decreased in both strains (Table 1). However, in D. bardawil $\mathrm{Chl}$ a decreased to a lesser extent in comparison with $\mathrm{Chl} b$, which resulted in an increased $\mathrm{Chl} a / b$ ratio.

$P_{\text {MAX }}$, measured as oxygen production, declined rapidly in both strains after growth arrest, with or without DPA (Fig. 4a). The light utilization efficiency $(\alpha)$, on the other hand, showed a rapid decrease in $D$. salina, but a slight increase in D. bardawil (Fig. 4b), which was maintained for about $4 \mathrm{~d}$. This increase was completely inhibited by 


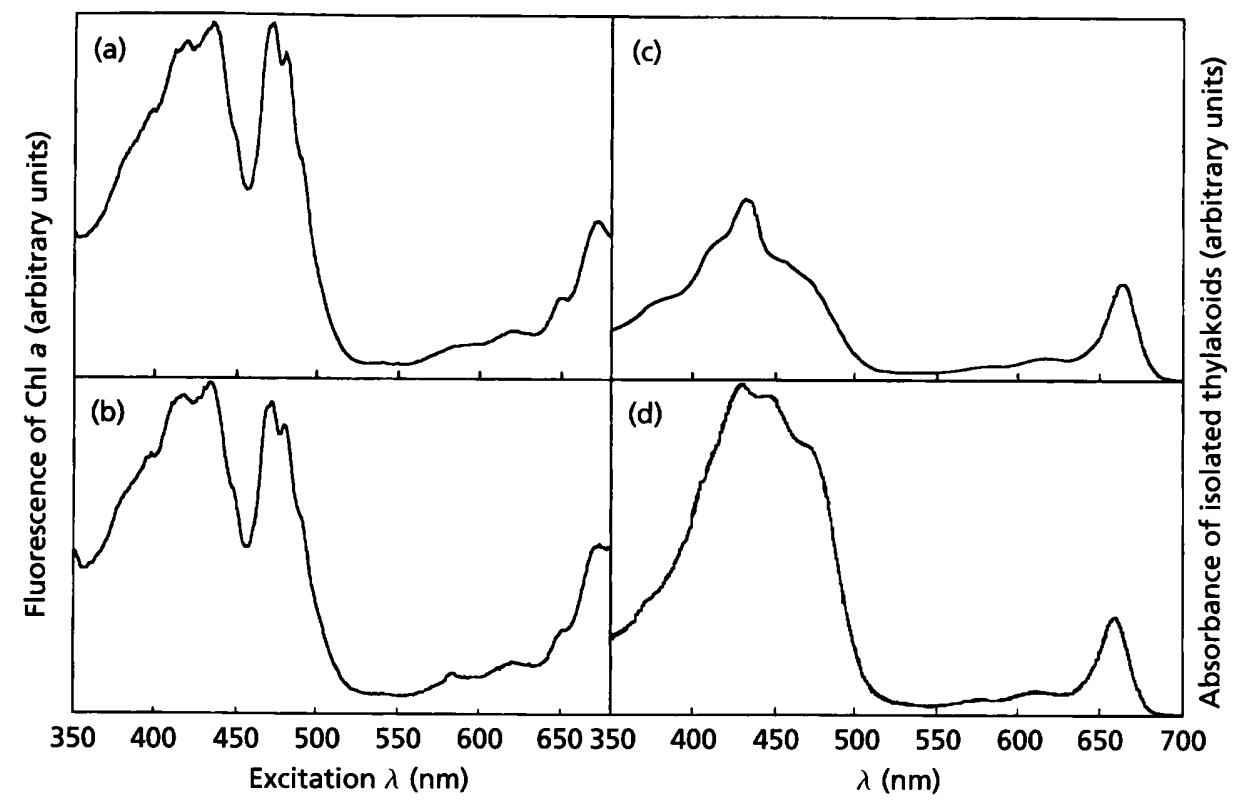

Fig. 5. Excitation fluorescence spectra and absorption spectra of isolated thylakoids. $(a, b)$ Excitation fluorescence of thylakoids at day 0 (a) and day 4 (b); (c, d) absorption spectra of isolated thylakoids at day 0 (c) and day 4 (d). Isolated thylakoids were extracted in $80 \%$ acetone and absorption spectra were measured in a Perkin-Elmer Hitachi 200 spectrophotometer.

DPA, implying a causal relationship between enhanced carotenogenesis and the temporary increase of photosynthetic efficiency. However, even though it was demonstrated that a proportion of the accumulated carotenoids (especially lutein and zeaxanthin) was located in the thylakoid membrane, it seems improbable that they took part in the light-harvesting process. Excitation fluorescence spectra of isolated functional thylakoids of $D$. bardawil before and after growth arrest showed no difference in the contribution of light-harvesting pigments to the excitation profile of $\mathrm{Chl} a$ (Fig. 5).

\section{DISCUSSION}

In nitrogen-limited chemostat cultures of two Dunaliella species, grown under moderate light intensities, growth arrest resulted in an immediate and dramatic rise in carotenoid content in D. bardawil, but not in D. salina. The maximum amount of carotenoids in $D$. bardawil was attained after about $6 \mathrm{~d}$. The predominant accumulated pigment was $\beta$-carotene, but lutein and zeaxanthin also increased. The increase of $\beta$-carotene and the minor carotenoids lutein and zeaxanthin in $D$. bardawil in stress conditions has been reported previously, for example after transfer from low-light to high-light (Lers et al., 1990) or low-salt to high-salt conditions (Gómez-Pinchetti et al., 1992; Borowitzka et al., 1990). In the D. bardawil strain used here, the levels of $\alpha$-carotene were extremely low, in contrast to studies by other groups reporting $\alpha$ carotene levels of $2.5 \%$ or higher (Ben-Amotz et al., 1988; Erazo et al., 1989).

The ratio total carotene over thylakoid-associated carotene in Table 2 is normalized to Chl content, because the isolation and purification of thylakoids is so lengthy that considerable losses occurred and budgeting was impractical. This could be done because it is reasonable to assume that all $\mathrm{Chl}$ is in the thylakoids. Although most of the stress-produced $\beta$-carotene was located in oily globules inside the stroma fraction of the chloroplast, a substantial fraction of $\beta$-carotene and essentially all the lutein and zeaxanthin were bound to the thylakoid fraction of the chloroplast. The amount of carotene in the thylakoid fraction reached a maximum at day 3 after growth arrest and did not increase further. Although the amount of accumulated carotene in the oily globules is considerably higher than in the thylakoid fraction and even continued to increase after day 3 of growth arrest, it cannot be excluded a priori that the accumulated carotene in the thylakoid fraction is involved in the light-harvesting process. This observation is interesting in view of the finding by Lers et al. (1991) that induction of carotenogenesis is accompanied by the increase of a transcript that is closely related to early light-induced genes of higher plants and whose translational product might function as a pigment-binding protein whose synthesis is co-ordinately regulated with carotenogenic enzymes.

In most higher plants and green algae, the reaction centres and light-harvesting complexes decrease more or less proportionally during nutrient stress; therefore the $\mathrm{Chl}$ $a / b$ stoichiometry remains rather constant (Anderson, 1986; Siefermann-Harms, 1985; Thornber et al., 1991). Dunaliella is exceptional in having a high $\mathrm{Chl} a / b$ ratio (Sukenik et al., 1987). Growth arrest results in a decrease of Chl $a$ and $b$ content, which might reflect a decrease in the number and/or size of the photosystems and lightharvesting complexes. This is accompanied by a decrease 
in photosynthetic $\mathrm{O}_{2}$ evolution. However, compared to $D$. salina, $D$. bardawil exhibits a temporary increase in the Chl $a / b$ ratio, which implies a slower decrease in the number of photosystems. This increase in the Chl $a / b$ ratio is not present when cells are incubated with DPA. Since DPA is quite specific in inhibiting the increase of carotenoid content, this implies that the altered $\mathrm{Chl} a / b$ ratio is connected with the increase of carotenoids after growth arrest. This phenomenon is accompanied by a temporary apparent increase of photosynthetic efficiency, reflecting an increased efficiency of electron transport.

Irrespective of the mechanism by which the temporary increase of photosynthetic efficiency is brought about, it is possible that the relatively large demand of reducing equivalents required for carotenoid biosynthesis might influence the photosynthetic efficiency. This contention is supported by the fact that DPA also blocks the increase in photosynthetic efficiency. In this way, the accumulated carotenoids, of which the bulk is located in oily globules, might serve as an electron sink. Another possibility is that the stress-induced carotenoids function as a screen to protect the photosystems from photochemical degradation (Ben-Amotz et al., 1987, 1989). The low-light intensities used in our experiments make such a hypothesis less probable. Zeaxanthin is more directly involved in protection of the photosystems, but only in situations where photo-inhibition of photosynthesis occurs (Demmig-Adams, 1990; Neubauer \& Yamamoto, 1992). Zeaxanthin, which is formed by de-epoxidation of violaxanthin via antheraxanthin in the xanthophyll cycle is involved in the radiationless dissipation process of excess excitation energy. By protecting the photosystems it is possible that the temporary increase in photosynthetic efficiency in $D$. bardawil could be maintained for a prolonged period of time. It is unlikely that this is the mechanism by which the temporary increase in photosynthetic efficiency in $D$. bardawil can be explained because: (1) the cells were grown under moderate light intensities (2) the amounts of violaxanthin and antheraxanthin were much lower than the amount of zeaxanthin, and (3) their abundances did not change significantly.

The question arises whether the stress-accumulated carotenoids, in particular lutein, become involved in the lightharvesting process, which is implied by the fact that they are associated with the thylakoid membrane fraction. Lutein has been reported to be an integral part of LHCII (Sukenik et al., 1988; Siefermann-Harms, 1985). Recently Bassi et al. (1993) reported lutein to be bound to proteins CP47 and CP43 of photosystem II. However, the fact that excitation spectra of isolated thylakoids of $D$. bardawil before and after growth arrest did not show an increased contribution of light-harvesting pigments to the $\mathrm{Chl} a$ fluorescence contradicts this possibility.

\section{ACKNOWLEGEMENTS}

We wish to thank Hans Matthijs (Department of Microbiology, University of Amsterdam) for helpful discussions, Martin Kooijman (Department of Biophysics, Free University, Amster- dam) for his help with the excitation fluorescence spectra and the Department of Plant Physiology of the Free University for the use of their spectrofluorometer.

\section{REFERENCES}

Anderson, J. M. (1986). Photoregulation of the composition, function, and structure of thylakoid membranes. Annu Rev Plant Pbysiol 37, 93-136.

Bassi, R., Pineau, B., Dainese, P. \& Marquardt, J. (1993). Carotenoid-binding proteins of photosystem II. Eur J Biochem 212, 297-303.

Ben-Amotz, A., Katz, A. \& Avron, M. (1982). Accumulation of $\beta$ carotene in halotolerant algae: purification and characterization of $\beta$-carotene-rich globules from Dunaliella bardawil(Chlorophyceae). $J$ Pbycol 18, 529-537.

Ben-Amotz, A., Gressel, J. \& Avron, M. (1987). Massive accumulation of phytoene induced by norflurazon in Dunaliella bardawil (Chlorophyceae) prevents recovery from photoinhibition. J Pbycol 23, 176-181.

Ben-Amotz, A., Lers, A. \& Avron, M. (1988). Stereoisomers of $\boldsymbol{\beta}$ carotene and phytoene in the alga Dunaliella bardawil. Plant Pbysiol 86, 1286-1291.

Ben-Amotz, A., Shaish, A. \& Avron, M. (1989). Mode of action of the massively accumulated $\beta$-carotene of Dunaliella bardawil in protecting the alga aginast damage by excess irradiation. Plant Pbysiol 91, 1040-1043.

Borowitzka, M. A., Borowitzka, L. J. \& Kessley, D. (1990). Effects of salinity increase on carotenoid accumulation in the green alga Dunaliella salina. J Appl Pbycol 2, 111-119.

Demmig-Adams, B. (1990). Carotenoids and photoprotection in plants: a role for the xanthophyll zeaxanthin. Biochim Biophys Acta 1020, 1-24.

Dubinsky, Z., Falkowski, P. G., Post, A. F. \& Van Hes, U. M. (1987). A system for measuring phytoplankton photosynthesis in a defined light field with an oxygen electrode. J Plankton Res 9, 607-612.

Erazo, S., Proust, P., Viani, M. \& Müller, K. (1989). Estudio de la biomasa y de los pigmentos carotenoides contenidos en una especie nativa de la microalga Dunaliella salina sp. Rev Agroquim Tecnol Aliment 29, 538-547.

Falkowski, P. G. (1984). Kinetics of adaptation to irradiance in Dunaliella tertiolecta. Photosynthetica 18, 62-68.

Gómez-Pinchetti, J. L., Ramazanov, Z., Fontes, A. \& García-Reina, G. (1992). Photosynthetic characteristics of Dunaliella salina (Chlorophyceae, Dunaliellales) in relation to $\beta$-carotene content. $J$ ApplPhycol 4, 11-15.

Harris, E. H. (1989). Culture and storage methods. In The Chlamydomonas Sourcebook, pp. 25-64. Edited by E. H. Harris. London: Academic Press.

Herbert, D., Phipps, P. J. \& Strange, R. W. (1971). Chemical analysis of microbial cells. Metbods Microbiol 5B, 209-844.

Kempers, A. J. \& Luft, A. G. (1988). Re-examination of the determination of environmental nitrate as nitrite by reduction with hydrazine. Analyst 113, 1117-1120.

Kleinig, H. (1989). The role of plastids in isoprenoid biosynthesis. Annu Rev Plant Pbysiol Plant Mol Biol 40, 39-59.

Korthals, H. J. \& Steenbergen, C. L. M. (1985). Separation and quantification of pigments from natural phototrophic microbial populations. FEMS Microbiol Ecol 31, 177-185. 
Koyama, Y. (1991). Structures and functions of carotenoids in photosynthetic systems. J Photochem Photobiol B Biol 9, 265-280.

Lers, A., Biener, Y. \& Zamir, A. (1990). Photoinduction of massive $\beta$-carotene accumulation by the alga Dunaliella bardawil. Plant Pbysiol 93, 389-395.

Lers, A., Levy, H. \& Zamir, A. (1991). Co-regulation of a gene homologous to early light-induced genes in higher plants and $\beta$ carotene biosynthesis in the alga Dunaliella bardawil. J Biol Chem 266, $13698-13705$.

Lichtenthaler, H. K. (1987). Chlorophylls and carotenoids: pigments of photosynthetic biomembranes. Methods Enzymol 148, 350-382.

Loeblich, L. A. (1982). Photosynthesis and pigments influenced by light intensity and salinity in the halophile Dunaliella salina (Chlorophyta). J Mar Biol Assoc UK 62, 493-508.

Neubauer, C. \& Yamamoto, H. Y. (1992). Mehler-peroxidase reaction mediates zeaxanthin formation and zeaxanthin-related fluorescence quenching in intact chloroplasts. Plant Physiol 99, $1354-1361$.

Siefermann-Harms, D. (1985). Carotenoids in photosynthesis. I. Location in photosynthetic membranes and light-harvesting function. Biochim Biopbys Acta 811, 325-355.

Sukenik, A., Wyman, K. D., Bennett, J. \& Falkowski, P. G. (1987).
A novel mechanism for regulating the excitation of photosystem II in a green alga. Nature 327, 704-707.

Sukenik, A., Bennett, J. \& Falkowski, P. G. (1988). Changes in the abundance of individual apoproteins of light-harvesting chlorophyll $a / b$-protein complexes of Photosystem I and II with growth irradiance in the marine chlorophyte Dunaliella tertiolecta. Biochim Biopbys Acta 932, 206-215.

Thornber, J. P., Morishige, D. T., Anandan, S. \& Peter, G. F. (1991). Chlorophyll-carotenoid proteins of higher plant thylakoids. In Chlorophylls, pp. 549-585. Edited by H. Scheer. London: CRC Press.

Van der Staay, G. W. M., Brouwer, A., Baard, R. L., van Mourik, F. \& Matthijs, H. C. P. (1992). Separation of Photosystems I and II from the oxychlorobacterium (prochlorophyte) Procblorotrix bollandica and association of chlorophyll $b$ binding antennae with Photosystem II. Biochim Biopbys Acta 1102, 220-228.

Wiese, L. (1965). On sexual agglutination and mating-type substances (gamones) in isogamous heterothallic Chlamydomonads. I. Evidence of the identity of the gamones with the surface components responsible for the flagellar contact. J Phycol 1, 46-54.

Received 18 October 1993; revised 3 January 1994; accepted 11 January 1994 